\title{
Gonzalo Rodríguez Lafora y la histopatología de la poliomielitis epidémica (1913)
}

\section{Gonzalo Rodríguez Lafora and the histopathology of the epidemic poliomyelitis (1913)}

\section{Gonzalo Rodríguez Lafora e histopatologia da epidemia de poliomielite (1913)}

\author{
Francisco Herrera-Rodríguez \\ Facultad de Enfermería y Fisioterapia (Universidad de Cádiz)
}

Cómo citar este artículo en edición digital: Herrera-Rodríguez, F. (2016). Gonzalo Rodríguez Lafora y la histopatología de la poliomielitis epidémica (1913). Cultura de los Cuidados (Edición digital), 20( 46).

Disponible en: < http://dx.doi.org/10.14198/cuid.2016.46.04>

Correspondencia: Francisco Herrera-Rodríguez. Facultad de Enfermería y Fisioterapia. Avda. Ana de Viya, 52. 11009-Cádiz.

Correo electrónico: francisco.herrera@uca.es

(Trabajo realizado en el marco del proyecto HAR2012-39655-C04-03 del MINECO)

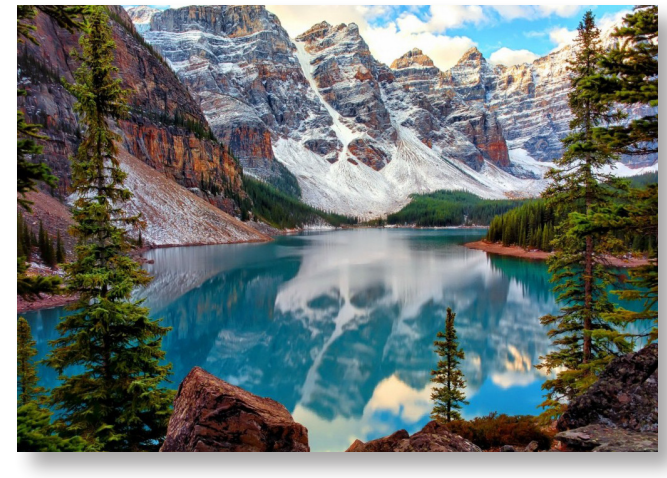

ABSTRACT

Gonzalo Rodríguez Lafora (1886-1971) is considered to be one of the most notable medical figures of the Generation of 1914. Between 1910 and 1912 worked at "Saint Elizabeth Hospital" in Washington. In 1910 a polio epidemic took place in that city. Lafora wrote an article about the epidemic which was published in Spain in 1913, although, previously, he had made some submissions on the subject in English and German languages.

Key words: Gonzalo Rodríguez Lafora, Generation of 1914, History of Medicine, Histopathology, Polio, XX century, Washington, USA, Spain.

\section{RESUMO}

Gonzalo Rodríguez Lafora (1886-1971) é uma das figuras mais notáveis médicos da Geração de 1914. Entre 1910 e 1912 trabalhou no "Santo Elizabeth Hospital" em Washington. Em 1910 realizou-se nesta cidade uma epidemia de poliomielite que causou um artigo de Lafora, que viu a luz em Espanha em 1913, embora feito anteriormente apresentações sobre o tema em Inglês e Alemão.

Palavras-chave: Gonzalo Rodríguez Lafora, Geração de 1914, História da Medicina, Histopatologia, Pólio, do século XX, Washington, EUA, Espanha.

\section{RESUMEN}

Gonzalo Rodríguez Lafora (1886-1971) es una de las figuras médicas más notable de la llamada Generación de 1914. Entre 1910 y 1912 trabajó en el "Saint Elizabeth Hospital" de Washington. En 1910 se desarrolló en esta ciudad una epidemia de poliomielitis que propició un artículo de Lafora, que vio la luz pública en España en 1913, aunque previamente realizó comunicaciones sobre el tema en inglés y alemán. 
Palabras clave: Gonzalo Rodríguez Lafora, Generación de 1914, Historia de la Medicina, Histopatología, Poliomielitis, siglo XX, Washington, EE UU, España.

\section{INTRODUCCIÓN}

Gonzalo Rodríguez Lafora (1886-1971) es una de las figuras más notables de la medicina española del siglo XX (figura 1); su nombre va indisociablemente unido a un "cuadro clínico", Enfermedad de Lafora, así como a la escuela histológica de Cajal y al magisterio de Nicolás Achúcarro (1880-1918). En esta breve nota no presentamos una biografía de Lafora ya que se puede consultar ampliamente en la bibliografía que se adjunta al final de este trabajo. Sí diremos que en 1908 la "Junta de Ampliación de Estudios" le concedió una beca para ampliar su formación neuropsiquiátrica en Alemania y también que a partir de mayo de 1910 trabajó en el "Saint Elizabeth Hospital" de Washington, institución en la que ocupó el puesto de Nicolás Achúcarro, desempeñándolo hasta septiembre de 1912. Valenciano Gayá apuntó que Lafora, al evocar su época de Washington, resaltaba la generosidad de los colegas americanos "para poner mutuamente a disposición material de estudio e ideas". Lafora regresó a España a finales de 1912 o a principios de 1913, con toda seguridad obligado por la enfermedad palúdica que padecía.

Precisamente fue Washington la ciudad en la que tuvo lugar una epidemia de poliomielitis en 1910, circunstancia por la cual Lafora realizó un interesante trabajo centrándose en los aspectos etiológicos y sobre todo histopatológicos de la enfermedad; artículo que fue publicado en España en 1913, pero que previamente comunicó en inglés y alemán; un trabajo sobre el que pensamos que no ha sido

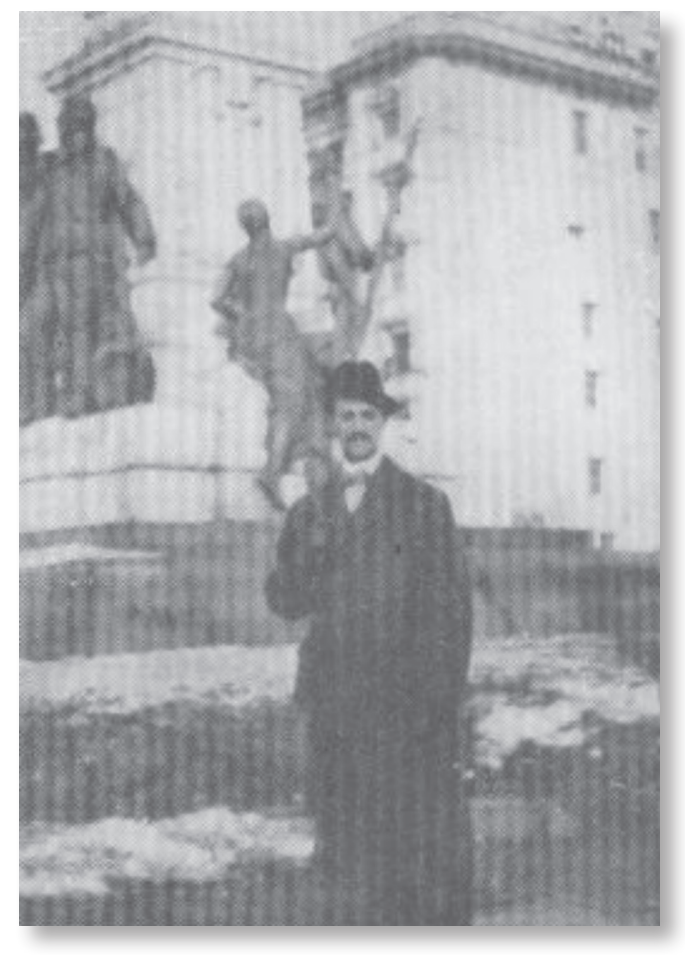

Figura 1: Gonzalo Rodríguez Lafora en Washington (1912) (Fuente: Valenciano Gayá, 1977)

considerado suficientemente por los historiadores en España (figura 2).

Notas para la histopatología de la poliomielitis epidémioa GONZALO R. LAFORA

Figura 2: Título del trabajo publicado por Rodríguez Lafora en "Trabajos del Laboratorio de investigaciones Biológicas de la Universidad de Madrid" (1913).

Según señala Glanzmann, entre 1905 y 1907 se sucedieron grandes epidemias en Suecia y Noruega, estudiadas y descritas por Ivar Wickmann. De los países escandinavos, donde la enfermedad estaba extendida desde hacía más de veinte años, pasó, en 1907-1909, a los Estados Unidos y Canadá. A partir de 1905 la 
enfermedad se extendió, comenzando la aparición de epidemias de miles de casos en Suecia, Noruega, Austria, Alemania y América del Norte. En este contexto creemos que se debe estudiar la referida epidemia de Washington de 1910 .

\section{CONSIDERACIONES ETIOLÓGICAS E HISTOPATOLÓGICAS SOBRE LA POLIO- MIELITIS EPIDÉMICA}

En 1910, como hemos indicado, la ciudad de Washington y el Distrito de Columbia padecieron una epidemia de poliomielitis, en el transcurso de la misma enfermaron 512 personas y murieron 16. Comenzó el brote epidémico en el mes de junio y fue disminuyendo de forma progresiva durante el verano. La enfermedad hizo daño tanto en la ciudad como en la campiña de los alrededores.

Gonzalo Rodríguez Lafora, en una breve nota, publicó en 1913 en la revista “Trabajos del Laboratorio de Investigaciones Biológicas de la Universidad de Madrid", el citado trabajo (figura 2); dedica muy poco espacio en el mismo a la etiología de la enfermedad, pero el suficiente para afirmar que la enfermedad es debida a un "germen", aunque lo apunta de forma muy genérica, esto lo entenderemos más adelante cuando comentemos su opinión sobre la posible etiología "protozóica" de la enfermedad:

"Que la poliomielitis epidémica es debida á un germen, parece haber sido demostrado recientemente por Noguchi, su descubridor, quien ha encontrado, en unión de Flexner, unos corpúsculos redondos en cadeneta, habiéndolos inoculado con éxito cultivos puros de los mismos".

Lafora no tiene duda de que la etiología de la enfermedad es de origen infeccioso $y$, por tanto, transmisible; hecho que, según apun- ta, ha sido determinado gracias al estudio de casos durante las epidemias de Viena, Breslau, New York, París y Victoria. Como acabamos de apuntar es prudente en lo que se refiere al "germen" que causa la enfermedad, no entrando de momento en consideraciones sobre su condición vírica o bacteriana, en cambio es muy minucioso con el objetivo principal de su artículo, estudiar la histopatología de la poliomielitis; hecho muy meritorio dado que sobre este particular existían pocos trabajos publicados, destacando los de Wickmann, Strauss, Lhermitte, además de los estudios experimentales de Levaditi y Flexner. Sobre este último aspecto en su nota el autor madrileño no cita nominalmente a Landsteiner; aunque, por ejemplo, González Rodríguez, en 1953, señaló que el poder patógeno experimental del virus fue establecido desde 1908 por Landsteiner y Popper, por inoculación al mono; efectuándose estudios sobre la conservación de dicho poder patógeno, por "pases" de mono a mono, por Flexner, Römer, Landsteiner y Levaditi. Los trabajos de Armstrong fueron importantes también ya que logró infectar a la rata algodonera con el virus procedente de un caso mortal de poliomielitis, ocurrido en Lansing, después de algunos "pases" por monos.

El trabajo de Lafora se basa en primer lugar en el estudio del líquido cefalorraquídeo de once casos de la citada epidemia y el estudio de la médula de una persona fallecida en el período agudo de la enfermedad. Estudio que realiza en unión del Dr. Hough, aunque el artículo que comentamos solo aparece firmado por Lafora y no recoge al final del mismo bibliografía aclaratoria. En cambio, Gonzalo Moya, en su recopilación bibliográfica de los trabajos de Rodríguez Lafora, apunta que éste publicó con William H. Hough dos trabajos relacionados con la poliomielitis: en 1910 el 
titulado "The cerebroespinal fluid in acute anterior poliomielitis", y en 1911 "Some findings in the cerebrospinal fluid in eleven cases of acute anterior poliomielitis". En este último año Lafora, en solitario, publicó en "Washington $\mathrm{Me}$ dical Annals", un artículo titulado "Histopathological report of a case of poliomielitis anterior epidémica". Y en 1913 en alemán: "Zur histopathologie der juvenilen paralyse mit mitteilun zweier Fälle".

El estudio del líquido cefalorraquídeo, según apunta Lafora, demuestra que en los primeros días existe un gran aumento de los leucocitos polinucleares y del contenido de proteína, aunque la "polinucleosis" desaparece a los pocos días, "quedando solo una pleocitosis dependiente del aumento de los linfocitos". Lafora interpreta la desaparición tan rápida de los polinucleares por un fenómeno de destrucción de los mismos llevado a cabo por las células macrófagas de naturaleza endotelial y linfocítica. En el estudio microscópico parece corroborarse este hecho al observar aglomeraciones de células macrófagas que contienen en su protoplasma numerosos núcleos de polinucleares. Sobre las técnicas de tinción cita el método de Pappenheim, aunque no se detiene en sus fundamentos metodológicos. Según avanza la enfermedad aparecen abundantes células plasmáticas y células cebadas de Ehrlich:

"...hecho este que nos hizo pensar en la posibilidad de la naturaleza protozóica del germen productor, pues si bien no con constancia (puesto que se exceptúa la tuberculosis meníngea), estas células aparecen en el líquido cefalorraquídeo en enfermedades de esta naturaleza, en tanto que los polinucleares representan el tipo de reacción meníngea á los gérmenes microbianos".

Conviene comentar, pues, algunas cuestiones sobre la posible naturaleza "protozóica” del germen productor. Rodríguez Lafora, como se puede apreciar en el párrafo precedente, opina sobre la etiología de la enfermedad, pero ofrece más detalles sobre la patogenia. Sobre este particular considera que la presencia de polinucleares en gran cantidad, durante los primeros días de la enfermedad, corresponde quizás a la reacción meníngea contra el germen, y señala que las meninges constituyen "probablemente la puerta de entrada del germen (á través de sus vasos y espacios linfáticos), pues en ellas se observan los fenómenos inflamatorios más acentuados, sobre todo, en los enfermos fallecidos en los primeros días".

Rodríguez Lafora subraya que nunca consiguió encontrar especies bacterianas y señala que los datos aportados sobre el líquido cefalorraquídeo son de interés diagnóstico, "pues es sabido que las epidemias de poliomielitis suelen con frecuencia coincidir con epidemias de meningitis cerebro-espinal, dando lugar á confusiones en el diagnóstico clínico, como así en el tratamiento". Defiende, pues, que el estudio del líquido cefalorraquídeo es el único medio de hacer el diagnóstico diferencial, puesto que en la meningitis existe siempre una gran polinucleosis, ausencia de células plasmáticas, presencia del meningococo y mayor opalescencia del líquido; aunque existen casos en que "se presentan conjuntamente ambas afecciones, $y$ en éstos las dificultades diagnósticas son superiores".

El estudio de la médula espinal de un enfermo fallecido durante el periodo agudo de la enfermedad permite a Lafora hacer consideraciones histopatológicas. Macroscópicamente las meninges de la médula aparecen engrosadas, muy especialmente la piamadre con los vasos dilatados. La sustancia gris muy congestionada, con hemorragias capilares abundantes. Y un matiz que considera de gran interés: "Las astas anteriores eran las más afectadas, si 
bien en el engrosamiento lumbar las lesiones se extendian á la parte anterior de las astas posteriores. Las lesiones aparecían más acentuadas en la porción lumbar y engrosamiento cervical. En cambio, en la médula dorsal eran mucho menos marcadas, pero acentuándose en el lado derecho...”.

El estudio microscópico que presenta Lafora es muy detallado, circunstancia que también hemos podido comprobar en su tesis doctoral, defendida en 1914, sobre la "Enfermedad de Alzheimer". Lafora observa, en los cortes histológicos de la médula del enfermo fallecido por poliomielitis, una infiltración masiva de los vasos de las astas anteriores con numerosos linfocitos y células plasmáticas, "muchas de las cuales salen al tejido circundante, y en la necrosis del tejido, con producción de abundantes células granulo grasientas y macrófagos, conteniendo restos de células y de tejidos, y además productos de desintegración múltiples". Del asta anterior la zona menos lesionada es el núcleo antero-externo donde se observan células nerviosas en diversos estados de degeneración.

Llama la atención del médico madrileño que en el tejido necrosado de la sustancia gris se pierden las estructuras nerviosas y todo queda invadido por leucocitos polinucleares, por macrófagos y por numerosas células gránulo-grasientas. Y señala que entre estas "células de derribo" se encuentran unos cuerpos protoplasmáticos grandes, amorfos, "los cuales no tienen núcleo, pero que contienen numerosas vacuolas en las que están contenidos cuerpos cromáticos de forma variables" (figura 3).

Estas formaciones, según Lafora, se parecen a los cuerpos encapsulados de LeishmanDonovan del Kalaazar bovino, "pero su estudio detenido nos hace suponer que son masas nucleares de leucocitos polinucleares que, habiendo degenerado, son englobadas en estas formacio-

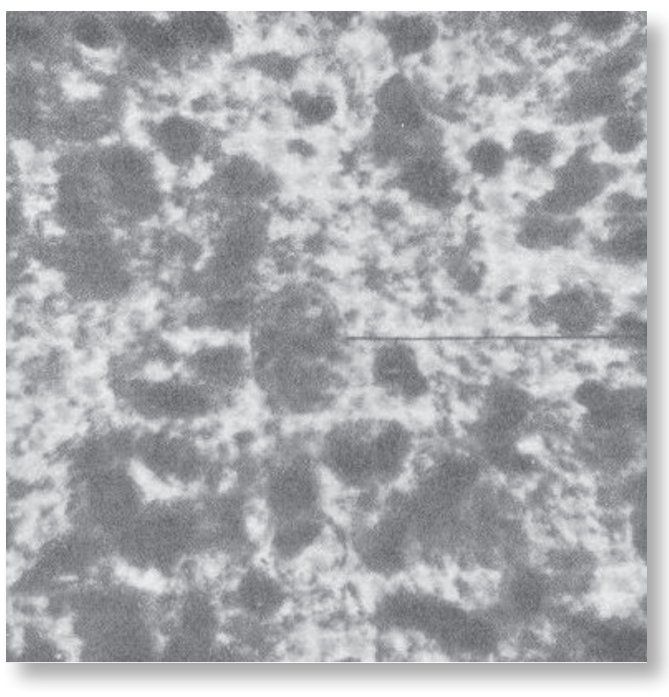

Figura 3: Poliomielitis epidémica. La flecha señala una masa protoplasmática grande conteniendo varios cuerpos cromáticos en su interior, hallada entre numerosas células granulo-grasientas y macrófagas en el foco degenerativo de la médula lumbar. Lafora apunta su semejanza con las formas encapsuladas de los Leishmanias (toluidina) (Fuente: Rodríguez Lafora, 1913)

nes protoplasmáticas". También apunta la existencia de unos cuerpos esféricos, probables restos nucleares, "que se encuentran aquí y allá entre la pulpa del foco necrótico, y que muestran apetencia por la pironina en vez de por el verde de metilo de la mezcla de Unna-Pappenhheim (pironinofilia)".

Asimismo comprueba la existencia de unos cuerpos de cromatina incluidos en vacuolas en el protoplasma de algunas células nerviosas, " $y$ que debido también á su eosinofilia accidental, han sido descritos por Proescher (New-York Medical Journal, Noviembre 1910) como parásitos semejantes á los cuerpos de Negri”. Rodríguez Lafora, en cambio, piensa que son núcleos de leucocitos o de linfocitos en diversas fases de degeneración que han penetrado en la célula nerviosa, "semejantes ó iguales á los descritos en la rabia por Achúcarro"; aunque no descarta que algunos sean células neuróglicas satéli- 
tes penetradas en las células nerviosas, "puesto que se observa neurofagia acentuada".

Como no podía ser de otra manera, Lafora, se detiene también en el estudio de la "substancia blanca" donde encuentra lesiones de interés. Observa vasos infiltrados, en menor cuantía que en la sustancia gris, y células en bastón abundantes en la proximidad del foco necrótico, otorgándole el médico madrileño una indudable naturaleza neuróglica. Y sobre todo apunta una alteración nuclear en algunas células nerviosas alejadas del foco necrótico. Esta alteración "consiste en la multiplicación de la substancia acidófila del nucléolo, la cual formaba dos y tres esférulas en vez de una única, como constituye la regla en las células nerviosas del asta anterior y posterior de la médula" (figura 4).

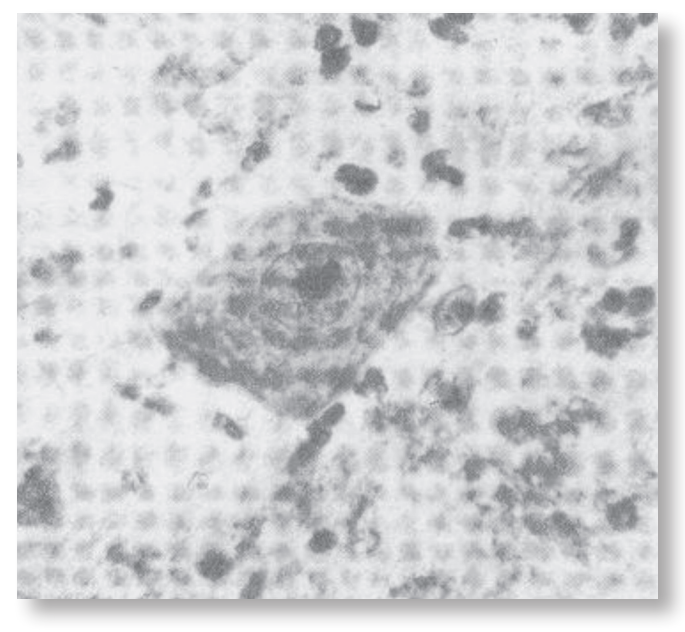

Figura 4: Poliomielitis epidémica. Célula motora del asta anterior de la médula lumbar, mostrando una marcada hipertrofia de la parte acidófila del nucléolo (método de la toluidina). (Fuente: Rodríguez Lafora, 1913)

Explica este hallazgo apoyándose en los trabajos de Levi que describió en el nucléolo de las células nerviosas humanas una porción central acidófila y unos grumos periféricos basófilos que, en número de tres o más, se acoplan como caperuzas a la superficie de la esférula acidófila; pero, como observaron Siciliano, Achúcarro y Lentz, en las células nerviosas en casos de rabia, en ciertas lesiones del sistema nervioso estas dos partes constituyentes del nucléolo pueden proliferar, " $y$ entonces puede hallarse aumentada, ó la cantidad de substancia acidófila y la de la substancia basiófila, ó bien las dos”. En la poliomielitis, según Rodríguez Lafora, es la sustancia acidófila la que se encuentra en estado de proliferación. Otro apunte histopatológico observado es la multiplicación y engrosamiento de los "gránulos fuchsinófilos" de Altmann en las células nerviosas de los núcleos del puente y del bulbo.

Concluye su nota con una explicación patogénica que merece ser transcrita literalmente, ya que con la lectura de la misma se puede apreciar que en los primeros años de la segunda década del siglo XX Lafora trató de contribuir al conocimiento de la poliomielitis en los aspectos etiológicos de la enfermedad, pero sobre todo en los histopatológicos:

"De lo descrito se desprende que, á consecuencia de la penetración del germen por los espacios linfáticos de los vasos, se produce una gran infiltración de estos últimos, y, ulteriormente, la necrosis del tejido nervioso en la parte más afectada por el proceso (porción anterointerna del asta anterior de la médula) y fenómenos reactivos del tejido circundante, entre los que se manifiestan procesos progresivos en las células nerviosas".

Gonzalo Rodríguez Lafora es un miembro destacado de la Generación de 1914, como también lo fue Nicolás Achúcarro, Río Hortega, Gregorio Marañón, Novoa Santos, Ortega y Gasset o Ramón Gómez de la Serna, entre otros; su formación en Alemania, becado por la "Junta de Ampliación de Estudios", y su 
ejercicio profesional en Washington son una muestra del aperturismo científico que propició la sociedad española en los referidos años, que Lafora supo aprovechar realizando trabajos de gran nivel científico en torno a la "Enfermedad de Alzheimer" o más concretamente sobre la etiología e histopatología de la poliomielitis epidémica que hemos comentado en este artículo.

\section{FUENTE}

- Rodríguez Lafora, G. (1913). Notas para la histopatología de la poliomielitis epidémica. Trabajos del Laboratorio de Investigaciones Biológicas de la Universidad de Madrid, 75-79 (Biblioteca de la Facultad de Medicina de la Universidad Complutense de Madrid).

\section{BIBLIOGRAFÍA}

- Álvarez-Pelaez, R. (1986). Una gran figura de la Neuropsiquiatría española del siglo XX. Gonzalo Rodríguez Lafora. Revista de la Asociación Española de Neuropsiquiatría, 17, 305-309.

- Díaz-Rubio, M. (2000). 100 médicos españoles del siglo XX. Madrid: Industrial Farmacéutica Cantabria, 168169.

- García-Albea, E. (1998). Lafora y los dos primeros casos de enfermedad de Alzheimer publicados en España. Revista de Neurología, 157, 515-519.

- García-Albea, E., y Pérez Trullen, J.M. (2003). The Spanish school of Neurology and the First American Cases of
Alzheimer's Disease. Journal of the History of the Neurosciences, 4: 437-445.

- Glanzmann, E. (1946). La parálisis infantil epidémica (poliomielitis). Barcelona: Ediciones BYP.

- González Rodríguez, P. (1953). Aspectos epidemiológico y social de la poliomielitis. La parálisis infantil en España. Madrid: Dirección General de Sanidad.

- González-Cajal, J. (1987). La Neurohistopatología clínica en la obra de Lafora. En: R. Huertas., A.I. romero., y R. Álvarez (eds.), Perspectivas psiquiátricas. (pp.135-146) Madrid: CSIC .

- González-Cajal, J. (1988). Gonzalo Rodríguez Lafora: Breves notas biográficas. Revista AEN, 27: 675-695.

- Herrera Rodríguez, F. (2014). Una lectura de la tesis doctoral de Gonzalo Rodríguez Lafora sobre la Enfermedad de Alzheimer (1914). Llull. Revista de la Sociedad Española de Historia de las Ciencias y de las Técnicas, 80, 205-217.

- López Piñero, J.M. et al (1983). Diccionario histórico de la ciencia moderna en España. Barcelona: Península, Volumen II, 252-256.

- Moya, G. (1986). Gonzalo R. Lafora. Medicina y cultura en una España en crisis. Madrid: Ediciones de la Universidad Autónoma de Madrid.

- Nanduri, A.S. et al. (2008). The maestro don Gonzalo rodríguez-Lafora. Epilepsia, 6: 943-947.

- Valenciano Gayá, L. (1977). El doctor Lafora y su época. Madrid: Ediciones Morata.

- Vitoria Ortiz, M. (1977). Vida y obra del doctor Achúcarro. Bilbao: Editorial La Gran Enciclopedia Vasca.

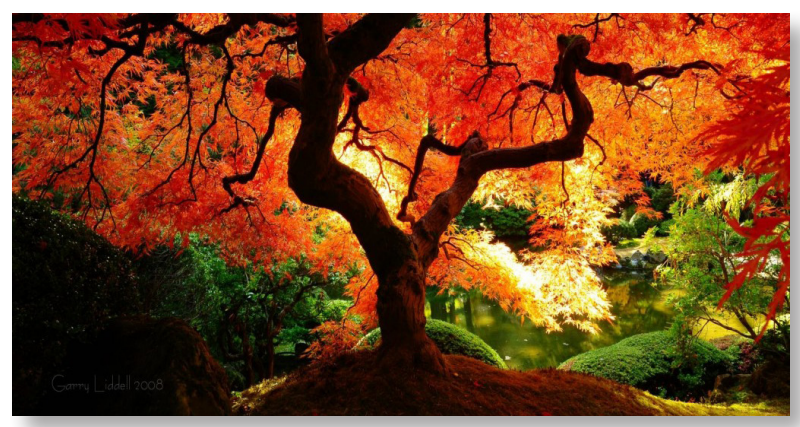

